\title{
Editorial: Our Love Affair with Technology and the Choices We Make
}

\author{
Seth S. Leopold MD
}

Received: 22 July 2014/ Accepted: 24 July 2014/Published online: 7 August 2014

(C) The Association of Bone and Joint Surgeons (B) 2014

Like a two-star mob movie or a love story gone awry, it seems that no sooner does our specialty learn from one mistake related to new technology than are we drawn back in for more drama. How can we make this bad movie stop?

This is a complicated question, and given the influences in play - both financial and academic - it may be difficult to resist the lure of new technologies. If we are to resist, we will need integrity on the part of those publishing on these topics, careful editing by journals, cautious reading by consumers of the research, and recognition that many practicing surgeons have a heavy incentive to embrace new technology before it is fully vetted. But without doubt, we have an obligation to do better.

In the Editor's Spotlight section this month, I wrote somewhat admiringly about a randomized trial comparing new custom cutting guides for knee arthroplasty surgery [4]. This was not because I feel strongly one way or the other about these instruments (I do not). Rather, my enthusiasm derived from the authors' balanced approach to presenting their findings. Pfitzner and colleagues found that the guides significantly improved implant alignment.

The author certifies that he, or any members of his immediate family, has no commercial associations (eg, consultancies, stock ownership, equity interest, patent/licensing arrangements, etc) that might pose a conflict of interest in connection with the submitted article.

All ICMJE Conflict of Interest Forms for authors and Clinical Orthopaedics and Related Research ${ }^{\mathbb{B}}$ editors and board members are on file with the publication and can be viewed on request.

The opinions expressed are those of the writers, and do not reflect the opinion or policy of $C O R R^{\circledR}$ or the Association of Bone and Joint Surgeons ${ }^{\circledR}$.

S. S. Leopold ( $\square)$

Clinical Orthopaedics and Related Research, Philadelphia, PA 19103, USA

e-mail: sleopold@ clinorthop.org
Despite these findings, they cautioned against the use of that expensive, new technology due to the small size of this "significant" effect [6].

Aseptic loosening from malaligned implants almost certainly occurs, but even this contention is controversial [5]; assuming that it does happen, it is by no definition a public-health menace, nor is it clear that a technology that improves alignment by a degree or three at a cost of hundreds or thousands of dollars per use is worth the investment. Kudos to Pfitzner et al. [6] for distinguishing between statistical significance and clinical importance.

But sadly, that sort of integrity is the exception, rather than the rule.

Some months ago in this space, I wrote about the important distinction between efficacy and safety [3], and made the point that most clinical research is powered to determine whether a treatment works, but not that it is safe when exposed to a large population of patients. Here, I am making a finer but as-important distinction: Not all differences in efficacy matter, or matter enough to be worth paying for, whether we pay in dollars or uncertainty.

Journals need to do a better job of pushing authors to acknowledge the difference between statistical findings and clinically meaningful results. At $C O R R^{\mathbb{R}}$, we will strive to point out this distinction. Readers need to pay attention to this critical issue, since editors are not infallible. As always, caveat lector - let the reader beware.

A more-philosophical question is, why do authors - why do we - need to be nudged in this way? The market economy thrives on innovation, and innovation is rewarded, sometimes generously, with consulting arrangements, royalties, and other inducements to participate, and promote, sometimes aggressively. But when the new approach fails, it is the patient, not the innovator, who pays the price, and on some big choices, we have gone wrong. As a 
specialty, we would often have been better off moving at a more pragmatic pace. For decades now, registries have helped identify failed products and designs in ways that limited what might otherwise have been more-extensive harm [1, 7, 8]. These registries can guide conversations about value [2], although other study designs are necessary to help us understand just why some of those designs and products failed. Just the same, wider adoption of registries by nations currently without them would surely help.

However, most of us are neither innovators nor promoters of new devices or approaches. And most of us probably know enough to read for clinical importance and not merely statistical significance. Yet, as a population, we have been co-stars in this tragic love story. Why is this? The honest answer almost certainly lies in the fact that most surgeons are influenced by the biggest conflict of all: Most of us still are paid by the piece, and almost all of us enjoy operating. The application of new technology promotes and enlarges our own practices. How often do we hear, "If I don't use this, the patient will go across town to someone who does." We need to own up to this and to ask ourselves when, and how, can we make this bad movie end?

An editorial alone will not end it. It will take the efforts of the orthopaedic community as a whole: Scientists, readers, editors, and practicing surgeons all need to agree that this is a problem worth solving. Authors need to present their claims modestly. Readers should focus on effect sizes and clinical relevance; as the editor, I will try to do the same. When editors miss the ball - at $C O R R^{\circledR}$ or elsewhere - write a letter. Your comments are always welcome here, at eic@clinorthop.org. Finally, as surgeons, we need to be mindful when we use some new implant, technology, or approach as a practice-building move, and to do so only when we are certain - based on thoughtful reading and evaluation - that it really clears the bar in terms of safety and efficacy. If we cannot turn off the projector, let's at least acknowledge that it is time to roll the credits.

\section{References}

1. Furnes O, Lie SA, Havelin LI, Vollset SE, Engesaeter LB. Exeter and charnley arthroplasties with Boneloc or high viscosity cement. Comparison of 1,127 arthroplasties followed for 5 years in the Norwegian arthroplasty register. Acta Orthop Scand. 1997;68: $515-520$

2. Gioe TJ, Sharma A, Tatman P, Mehle S. Do "premium" joint implants add value? Analysis of high-cost joint implants in a community registry. Clin Orthop Relat Res. 2011;469:48-55.

3. Leopold SS. Editorial: when "safe and effective" becomes dangerous. Clin Orthop Relat Res. 2014;472:1999-2001.

4. Leopold SS. Editor's Spotlight /Take-5: Small improvements in mechanical axis alignment achieved with MRI versus CT-based patient-specific instruments in TKA: A randomized clinical trial. Clin Orthop Relat Res. DOI: 10.1007/s11999-014-3848-7.

5. Parratte S, Pagnano MW, Trousdale RT, Berry DJ. Effect of postoperative mechanical axis alignment on the fifteen-year survival of modern, cemented total knee replacements. J Bone Joint Surg Am. 2010;92:2143-2149.

6. Pfitzner T, Abdel MP, von Roth P, Perka C, Hommel H. Small improvements in mechanical axis alignment achieved with MRI versus CT-based patient-specific instruments in TKA: A randomized clinical trial. Clin Orthop Relat Res. [Published online ahead of print July 15, 2014]. Clin Orthop Relat Res. DOI: 10.1007/ s11999-014-3784-6.

7. Puolakka TJ, Pajamäki KJ, Pulkkinen PO, Nevalainen JK. Poor survival of cementless Biomet total hip: a report on 1,047 hips from the Finnish Arthroplasty Register. Acta Orthop Scand. 1999;70:425-429.

8. Smith AJ, Dieppe P, Vernon K, Porter M, Blom AW; National Joint Registry of England and Wales. Failure rates of stemmed metal-on-metal hip replacements: analysis of data from the National Joint Registry of England and Wales. Lancet. 2012;379: 1199-204. 